\title{
Tracking blue cone signals in the primate brain
}

\author{
Jaikishan Jayakumar ${ }^{1}$, Bogdan Dreher ${ }^{2}$ \& Trichur R Vidyasagar $^{1}$ \\ ${ }^{1}$ Department of Optometry \& Vision Sciences and Melbourne Brain Centre, \\ University of Melbourne, Parkville, \\ Vic 3010, Australia. \\ ${ }^{2}$ School of Medical Sciences, University of Sydney, Sydney. \\ Corresponding author: TR Vidyasagar (trv@unimelb.edu.au)
}

Key words: Short-wavelength sensitive (S) cones; lateral geniculate nucleus; primary visual cortex; area MT; macaque. 


\section{Abstract}

In this paper we review the path taken by signals originating from the short wavelength sensitive cones (S-cones) in Old-World and New-World primates. Two types of retinal ganglion cells (RGCs) carrying S-cone signals (Blue-ON and Blue-OFF cells) project to the dorsal lateral geniculate nucleus (dLGN) in the thalamus. In all primates these S-cone signals are relayed through the 'dust-like' (konis in classical Greek) dLGN cells. In New-World primates such as common marmoset, these very small cells are known to form distinct and spatially extensive, koniocellular layers. Although in Old-World primates such as macaques, koniocellular layers tend to be very thin, the adjacent parvocellular layers contain distinct koniocellular extensions. It appears that all S-cone signals are relayed through such konio cells whether they are in the main koniocellular layers or in their colonies within the parvocellular layers of the dLGN. However, in the primary visual cortex, these signals begin to merge with the signals carried by the other two principal parallel channels, namely the magnocellular and parvocellular channels. This article will also review the possible routes taken by the S-cone signals to reach one of the topographically organized extrastriate visual cortical areas, the middle temporal area (area MT). This area is the major conduit for signals reaching the parietal cortex.

Alternative visual inputs to area MT not relayed via area V1 may provide the neurological basis for the phenomenon of 'blindsight' observed in human and non-human primates who have partial or complete damage to the primary visual cortex. S-cone signals to area MT may also play a role in directing visual attention with possible implications for understanding the pathology in dyslexia and some of its treatment options. 
In Old Word primates (including humans), photopic visual perception is largely based on the signals conveyed from three classes of cones via the retino-thalamo-cortical pathway. The cones are classified according to their spectral sensitivity peaks as Long (L), Medium (M) and Short (S) wavelength sensitive cones. Our chromatic perception is dependent upon how the brain processes variations in the activity among these photoreceptors. Chromatic signals in general are processed in two parallel streams, the red-green system by the parvocellular system ${ }^{1-6}$ (for reviews, see references 7 and 8 ) and the blue-yellow system by the koniocellular system ${ }^{6,9,10}$. Although substantial amount of work has been done to identify these processing streams in the retina and the dorsal lateral geniculate nucleus (dLGN) in the dorsal thalamus, our understanding of the blue-yellow chromatic system in the visual cortex is still at its infancy. This article briefly reviews the state of knowledge of the processing of the Scone signals in the visual brain of diurnal primates.

\section{Retinal processing of S-cone signals}

For a comprehensive review of the origins of the chromatic signals in the retina along with the retinal circuitry, see reference 8 . Briefly, the S-cone signal originates from the short-wavelength cone and even though the density of S-cones in the retina is far less than the density of the $\mathrm{L}$ or the M-cones, modulations of S-cone activity alone can provide a reasonably detailed level of visual perception ${ }^{11}$. The activity of S-cones is conveyed to the retino-recipient nuclei in the brain by so-called Blue-ON ( $\mathrm{S}+$ ) and the Blue-OFF (S-) retinal ganglion cells. Morphologically, the Blue-ON RGCs correspond to small bi-stratified $\mathrm{RGCs}^{12,13}$. Although it is still unclear how the Blue OFF signal is transmitted from the retina, at least some wide-field $\mathrm{RGCs}^{14}$ have been shown in the macaque to contain a blue light sensitive pigment (melanopsin) and 
transmit an irradiance signal (Blue off /Yellow on). However, it is not known how the short-wavelength signal from the $\mathrm{S}$ cones are transmitted to the Blue-OFF cells that have been identified in the marmoset $\mathrm{dLGN}^{15}$.

\section{Thalamic processing of S-cone signals}

In both Old-World and New-World monkeys, retinal axons carrying the S-cone signals appear to terminate exclusively in the koniocellular regions of the $\mathrm{dLGN}^{6,9}$. There are no reports of S-cone inputs from the retina directly to other brain regions such as the superior colliculus. Retinal axons to the dLGN carrying M- and L-cone signals terminate in the parvocellular and magnocellular regions of the $\mathrm{dLGN}^{3,4}$. Many cells of the parvocellular regions of the $\mathrm{dLGN}$ as well as the RGCs that project to them correspond to the Type 1 cells $^{1}$ that were first described by Hubel and Wiesel in the macaque dLGN. The characteristic feature of Type 1 cells is that the $\mathrm{L}$ and $\mathrm{M}$ cone signals are summed in anti-phase (spatial and chromatic opponency). In the magnocellular RGCs and dLGN cells, as in Type III cells of Wiesel and Hubel ${ }^{1}$, the $\mathrm{M}$ and L cone signals sum in-phase and there is little or no chromatic opponency between the centre and the surround ${ }^{1,4,9}$. The koniocellular regions of the dLGN contain a wide variety of neurones exhibiting quite heterogeneous characteristics. The blue-yellow opponent neurones constitute one of the major subtype within this system. An important distinction between the red-green opponent cells and the blueyellow opponent cells is that the blue/yellow opponency is made up of inputs from all three types of cones $[\mathrm{S}-(\mathrm{L}+\mathrm{M})$ or $(\mathrm{L}+\mathrm{M})-\mathrm{S}]$ and that the blue-yellow opponent cells do not show centre/surround opponency (Type II cells of Wiesel and Hubel ${ }^{1}$; cf. also 3.]. However, White and his colleagues ${ }^{16}$ described a subgroup of cells in the koniocellular layers of the dLGN of New-World diurnal monkeys (marmosets) whose 
responses to achromatic stimuli have spatial and temporal frequency characteristics somewhat intermediate between those of the spectrally non-selective parvocellular and magnocellular cells.

In New World diurnal monkeys, the koniocellular layers are fairly large and koniocellular cells are essentially not intermingled with those in the parvocellular or magnocellular layers. In Old World monkeys, such as macaques, the koniocellular layers are not only much thinner, but form strands or bridges that straddle the neighbouring parvocellular regions ${ }^{6,17,18}$. $\mathrm{We}^{6}$, have shown that in macaques dLGN neurones receiving the S-cone signal are not confined to the koniocellular layers proper but are also present in the koniocellular extensions into the neighbouring parvocellular regions.

\section{Insert figure 1 here}

Fig. 1A shows a coronal section through a macaque dLGN stained for Nissl substance (ribonucleic acid, RNA). The somata of neurones contain a lot of RNA and hence the cellular layers are clearly visible when the dLGN is stained for Nissl substance. Careful reconstruction of electrode track allowed us identification of dLGN layers in which functionally different types of cells were located. Compared to the magnocellular or the parvocellular layers, koniocellular layers show up as relatively pale areas, since the somata of cells in the koniocellular layers are not only small but they are also sparsely distributed. Figure 1B shows the photograph of the same dLGN section as that shown in Figure 1A. However, the picture has been defocussed using a Gaussian blur filter, since the koniocellular regions can then be easily visualised (Figure 1B). The two arrows mark the recording positions of two Blue-ON neurones (open blue circles). As evident from the figure, the bottom unit was recorded from the intercalated layer (K5) which is evident in the non-blurred 
picture. The relative position of the top unit however is unclear from Fig.1A but lies within the koniocellular strand that straddles between layers K4 and K5. These strands become obvious when the image is de-focussed (Fig. 1B), which can be done with an ordinary light microscope. Koniocellular neurones are to a large extent neurochemically distinct - unlike neurones in the parvocellular and magnocellular layers, a high proportion of relay cells in the koniocellular layers express the $28-\mathrm{kDa}$ calcium-binding protein, calbindin ${ }^{17,18}$. In the past, the putative presence of the koniocellular cells in the parvocellular islands of macaque's dLGN was inferred by the presence of scatterred calbindin expressing neurones in the parvocellular layers of $\mathrm{dLGN}^{17}$. Thus, the image de-focussing provides a simple way of demonstrating koniocellular regions in the macaque $\mathrm{dLGN}$ without using procedures such as staining for the calcium-binding protein, calbindin. It is likely that the very thinness of intercalated koniocellular layers plus existence of the koniocellular islands within the parvocellular laminae contributed strongly to the apparent 'mislocation' to the parvocellular layers of cells receiving S-cone inputs in early studies of the macaque $\mathrm{dLGN}^{1,3,4}$.

Irrespective of the region from which they were recorded (koniocellular layers themselves or the koniocellular extensions into the parvocellular layers), single neurones that carry S-cone signals tend to have receptive fields that are larger than those of parvocellular neurones ${ }^{6}$. Contrast sensitivity of these units to achromatic stimuli is also poorer than for parvocellular neurones. The magnitude of neuronal responses of these blue-yellow koniocellular neurones increases linearly with increments over a wide range of contrasts. In other words, the responses of koniocellular neurones which receive S-cone signals, like those of parvocellular neurones, but unlike those of the magnocellular neurones, do not saturate at relatively 
low $(30-40 \%)$ contrasts but continue monotonically up to $100 \%$ contrast when using sine wave gratings ${ }^{6}$.

Cells which constitute the Blue-OFF sub-pathway within the S-cone system exhibit considerable differences from those which constitute the Blue-ON sub-pathway. In general, these cells are known to be relatively "sluggish" compared to the Blue-ON cells $^{19}$. Their response rates have also been reported to be at least three times lower than those of the Blue-ON cells. While the centres of these cells receive L- and Mcone inputs, the S-cone input to the surround is often combined with other cone inputs to varying degrees in different cells. However, it is important to note that these BlueOFF cells are still found in the K-layers and are believed to be part of the so-called "W-like" system ${ }^{15}$ found in carnivores such as domestic cats ${ }^{20}$. Indeed in the domestic cat, the retinal ganglion cells and dLGN cells carrying the S-cone signals exhibit characteristics of $\mathrm{W}$ cells and in case of dLGN they are located exclusively in the Clayers, that is, koniocellular layers of carnivores ${ }^{21,22}$.

Latency of the response of a neurone to the appearance of a visual stimulus or to electrical stimulation applied earlier along the pathway, is a measure of the speed of transmission of the neural signal along that pathway. Thus the conduction velocity within the retino-geniculate pathway can be measured by recording the latency of the action potential in a dLGN cell evoked by electrical stimulation of the optic chiasm. This technique had revealed that in macaques, magnocellular signals always took less than $1.6 \mathrm{~ms}$ to travel from the chiasm to the dLGN while the parvocellular signals take considerably more than $2 \mathrm{~ms}^{3,23}$. However, Roy and colleagues ${ }^{6}$ found that the mean latencies of responses of koniocellular dLGN cells with S-cone input to electrical stimulation of optic chiasma were only slightly longer than those of red/green opponent parvocellular cells and even this difference was not statistically 
significant. This may seem a bit surprising since the smaller RGCs constituting the early part of the koniocellular pathway presumably have axons that are thinner and conducting more slowly than those of RGCs constituting the part of the parvocellular pathway. However, it is possible that if only one were to measure latencies to stimulation from a farther point such as the retina instead of the chiasm, difference in the response latencies of koniocellular and parvocellular might have become significant. Nevertheless, given the considerable overlap, conduction velocity cannot be used as a signature of koniocellular cells carrying S-cone signals though it has been a useful means for identifying magnocellular inputs ${ }^{3,23}$.

\section{Processing of S-cone signals in the primary visual cortex}

In primates, an overwhelming majority of the relay cells in the dLGN project to the primary visual cortex (striate cortex, cytoarchitectonic area 17 or area $\mathrm{V} 1$; for review see reference 24). The dLGN neurones carrying the red/green chromatic signals of the parvocellular system terminate in layers $4 \mathrm{~A}$ and $4 \mathrm{C} \beta$ of the primary visual cortex, while the axons of the magnocellular dLGN neurones terminate in layer $4 \mathrm{C} \alpha$ (for reviews see 25 and 26). These two pathways seem to be in accordance with the classical neuronal input schemes where the major dorsal thalamic inputs terminate in layer 4 common to most mammals ${ }^{27}$. On the other hand, axons from the koniocellular layers of the dLGN do not terminate in layer 4. Instead, the axons from the K-layers ventral to the two magnocellular layers ( $\mathrm{K} 1$ and $\mathrm{K} 2$ ) project to layer 1 and the superficial part of layer three ${ }^{28}$. The axons from K-layers ventral to the parvocellular layers of the dLGN (K3-K6) terminate within the so-called blob areas (that is, regions containing a lot of mitochondrial enzyme, cytochrome oxidase) of layer $2 / 3$ with some spill off in to the inter-blob areas and layer 1 (e.g. see figure 4 of reference 28). 
The importance of these K-layer projections to V1 is demonstrated by functional magnetic resonance imaging (fMRI) studies which have shown that the blue-yellow system, receiving input from only $10 \%$ of the cones, significantly modulates activity of area V1 of human observers ${ }^{29,30}$.

In their classical model of the chromatic organisation of the primary visual cortex Livingstone and $\mathrm{Hubel}^{31}$ proposed that there are two major parallel visual pathways, a chromatic pathway and an achromatic pathway, that remain segregated at the level of the primary visual cortex with the neurones with chromatic input being segregated within the supragranular blob areas. This model has been challenged on a number of counts. First of all, the third pathway, namely the koniocellular pathway, which has been fully recognized only some time after Livingstone and Hubel's proposal, needs to be accommodated within the scheme. Second, there is considerable opportunity for convergence of parvo- and magnocellular inputs if one studies the axonal arbours of geniculate afferents in the V1 and the extent of the dendritic tree of V1 cells ${ }^{32,33}$. There is also physiological evidence for convergence between different afferent pathways $^{23,34}$. Third, neurones with chromatic inputs have been found in the interblob parts of supragranular layers of area V1 that poorly stain for cytochrome oxidase $\mathrm{e}^{35}$.

Models of chromatic organisation of V1 initially also proposed that colour preference and orientation selectivity are coded separately ${ }^{31,36}$, but more recent experiments suggest that most colour selective cells in the primary visual cortex are also orientation selective $e^{23,37}$. There is also mixing of colour signals in V1, resulting in a wide variety of receptive field structures ranging from simple cone opponency similar to that observed in the dLGN neurones to complex structures such as double opponent cells ${ }^{38}$. 
In his seminal book published in 1982, David Marr ${ }^{39}$, one of the pioneers of what we now call computational neuroscience, pointed out that coding information about sub-parts of a visual scene in separate specialised parallel channels is far more efficient than coding information about all aspects of visual scene in a single channel. Thus, for natural selection, improvements, adaptations and debugging of any deleterious phenotypical consequences in a subpart is easier to accomplish within its corresponding channel than in a system where all sub-parts are carried within one channel and where complex compensating changes are necessary to ensure that only coding of one subpart is altered as per the need. However, in order to decode the information about visual scene adequately, mixing of information from the different parallel channels representing information along different dimensions, is essential at some level. As mentioned earlier, some of this mixing of information carried by the magnocellular and the other two afferent channels seems to occur already at the level of the primary visual cortex (e.g. see references 23 and 32-34). Some of this evidence relates also to the S-cone pathway as in the case of the example figure shown in the study by Vidyasagar and colleagues, where magnocellular and S-cone signals are shown to converge on a single cell (Fig. 4 of reference 23).

However, mixing of signals can also provide another advantage where the combined signals, that may include information from the parvocellular or koniocellular system, can be transmitted rapidly to the dorsal pathway, which can potentially provide behaviourally relevant, feedback to facilitate complex and selective processing of incoming sensory information as for example, in focal attention $^{40}$. This point will be elaborated further in the following section.

\section{Processing of S-cone signals in the extra-striate cortices of primates}


Colour perception is traditionally associated with the ventral or the 'what' or the 'perception' pathway ${ }^{41,42}$. The main cortical target for chromatic signals is area V4, which constitutes a part of and in fact a major gateway to, the ventral visual pathway and is generally believed to be also the main colour processing area in the primate brain (for review see reference 43). The classical 'dogma' has it that colour has little or no role to play in the dorsal, also referred to as the "where"41 or the 'action' 42 pathway which is dominated by the colour-blind luminance signals of the magnocellular channel ${ }^{44}$.

However, this classical model has been called into question with recent observations from area MT, an area that is considered an integral part of the Where/Action pathway. Studies on human observers using functional magnetic resonance imaging or $\mathrm{PMRI}^{45}$ and visually evoked potentials ${ }^{46}$ have shown that area MT receives S-cone inputs. There is also substantial electrophysiological evidence from studies in non-human primates that neurones in area MT receive a significant amount of S-cone signals ${ }^{47-51}$ (also, Jayakumar, Roy, Dreher, Martin \& Vidyasagar, under publication). It is also worth noting that in addition to the magnocellular and Scone signals, parvocellular signals from the dLGN also reach area MT, in this case presumably mainly via a disynaptic pathway, relaying via layer 6 of area $\mathrm{V} 1^{52}$.. It is also worth noting that $28 \mathrm{kD}$ calcium binding protein, calbindin which is expressed in the high proportion of the cells in the koniocellular layers of dLGN of macaques, is also strongly expressed in neurones located in the supragranular layers 2 and 3 of areas V1 and V2 of macaques ${ }^{18}$. Furthermore, calbindin immunopositive cells concentrate also in layers 2 and 3 of area MT of macaques ${ }^{53}$.

Although the evidence is fairly unequivocal that area MT does indeed receive Scone signals, it is still unclear as to what pathway these signals take. We have recently 
shown that the S-cone signals that project to macaque area MT reach it via V1 in some cases and bypassing V1 in others ${ }^{51}$ (also, Jayakumar, Roy, Dreher, Martin \& Vidyasagar, under publication). We reversibly inactivated V1 either by cooling it with a Peltier device or using iontophoretic application of the inhibitory transmitter, GABA and recorded from cells in the topographically corresponding part of area MT that received S-cone inputs. They showed that in many MT cells with S-cone inputs, during inactivation of area V1, the responses to S-cone signals did not change suggesting that these signals might be conveyed to area MT via an alternative pathway that bypasses area V1. In other MT cells however, S-cone signals to area MT appear to be routed through area V1, since inactivation of topographically corresponding parts of area $\mathrm{V} 1$ resulted in abolition or reduction of responses to visual stimuli that modulated exclusively the S-cones.

The most likely source of the S-cone signals to MT that bypass V1 is a direct projection from the dLGN to area MT, since it has been claimed that the number of axons in this projection is in fact about $10 \%$ of those projecting from V1 and arise from the koniocellular layers of the geniculate ${ }^{54}$. As mentioned earlier ${ }^{6}$, it is very likely that many of these koniocellular afferents to MT could carry S-cone signals, since in the macaque, S-cone signals travel almost exclusively through the koniocellular regions of the dLGN. It has also been shown in other studies that area MT remains active after complete ablation ${ }^{55}$ or reversible inactivation ${ }^{56}$ of ipsilateral area V1. However, combined removal of ipsilateral striate cortex and ipsilateral superior colliculus results in complete unresponsiveness of area MT to visual stimuli $^{57}$. It was suggested, that the visual signal from the superior colliculus relays through the pulvinar nucleus to MT. However, chromatically opponent signals seem 
to be absent in superior colliculus ${ }^{58-60}$. More recently, inactivation of dLGN has been shown to completely abolish all responses at the extra-striate areas ${ }^{61}$. Another source of visual inputs to the pulvinar is the retina itself ${ }^{62-67}$, but not only is this projection sparse but there are no indications so far that these projections could include S-cone signals. In summary, these studies make a direct projection from the dLGN to MT as one of the most likely paths for the S-cone signals to reach MT.

\section{Insert figure 2 here}

Figure 2 illustrates schematically the pathways taken by the S-cone signals to reach area MT. The S-cone signals from the retina reach the koniocellular regions of the dLGN. From the dLGN, the koniocellular projections that carry S-cone signals terminate either in layer 1 or in the cytochrome oxidase rich blobs of supragranular layers of area V1 with some overlap into the interblob regions. Classical model of chromatic organisation in V1 had proposed that these S-cone signals project to the thin cytochrome oxidase rich stripes of $\mathrm{V} 2$, which in turn project onto area $\mathrm{V} 4^{25}$. However, it is well known that there is significant mixing of the three pathways that happen either within V1 (see above) and/or in the V1 projection to area V2 compartments $^{68}$ and/or within area MT itself ${ }^{44}$. The relay of S-cone signals in V1 may be either via layer 1 where the koniocellular axons from dLGN contact apical dendrites of layer 4B cells or by the koniocellular afferents that stray into the interblob areas of layer $2 / 3^{28}$, which project to the thick cytochrome oxidase rich stripes in V2, which in turn project to area $\mathrm{MT}^{69}$.

\section{Implications of the S-cone pathway for behaviour}

The alternative input to area MT provides an explanation for the phenomenon of 'blindsight', a condition where some visual function still remains after complete loss 
of V1 in humans ${ }^{70-72}$. The patients usually have little awareness of visual stimuli, but in some situations, the stimuli can be shown to be processed in tasks that require access to some cortical areas. Many have postulated that blindsight is mediated by inputs to area MT that bypass $\mathrm{V} 1^{61,73-75}$. In this context, our finding ${ }^{51}$ (also, Jayakumar, Roy, Dreher, Martin \& Vidyasagar, under publication) is particularly relevant because a recent study on blindsight ${ }^{76}$ found that in the hemianopic field, Scone modulating stimuli were very effective, and in fact in one patient presentation of narrow band blue stimuli $(427 \mathrm{~nm})$ led to excellent performance but not red stimuli (peaking at $630 \mathrm{~nm}$ ). Furthermore Alexander $\&$ Cowey $^{76}$ found these stimuli were effective only if they came on suddenly rather than slowly. This is consistent with our own recent finding that area MT cells' response to S-cone modulation was apparent only for flashed stimuli but not for drifting stimuli ${ }^{51}$ (also, Jayakumar et al., under publication).

The koniocellular pathway ${ }^{77}$ and S-cones themselves ${ }^{78}$ can be considered in evolutionary terms as rather archaic. Though we do not know the fate of S-cone signals beyond the dLGN in carnivores such as the cat, the similarity of many response characteristics and the pattern of inputs and outputs indicate area PMLS (posteromedial lateral suprasylvian area) in the suprasylvian cortex in cats as the putative homologue of macaque area $\mathrm{MT}^{79,80}$. However, the fact that areas MT and PMLS are both important way-stations in the dorsal stream and that S-cone signals are carried exclusively by the koniocellular pathway, suggests that this pathway still plays an important role in visual perception. This is further supported by the finding that many S-cone inputs cells in area MT are also directionally selective ${ }^{49}$. Recent psychophysical evidence also suggests that visual attention can be directed better by 
stimuli activating the blue/yellow opponent pathway than by the red/green opponent pathway $^{81}$. While magnocellularly mediated achromatic signals are able to direct spatial attention far more efficiently when added to initially isoluminant red/green stimuli $^{82}$, addition of achromatic signals to blue/yellow elements in a visual search task do not confer any advantage ${ }^{81}$. Thus, the pathways carrying S-cone signals, being presumptively an early evolutionary invention, may have been co-opted to aid in focal spatial attention. This might have wider implications for pathologies involving the dorsal stream or its afferent inputs, especially with regard to the role of the dorsal stream in attention. One of the functions of the dorsal stream that has been discussed widely in recent years is its role in directing attention (e.g. see references 83 and 84) and in particular the possible role of posterior parietal regions in directing visuo-spatial attention for performing complex tasks such as reading ${ }^{40,85-90}$. It has been suggested that the basic pathology in dyslexia may be either a deficit in the magnocellular pathway that forms the dominant visual input to the dorsal stream or a lesion in the dorsal stream cortical areas themselves ${ }^{40,90,91}$. If so, since in visual search tasks, S-cone signals could direct spatial attention almost as well as magnocellular signals ${ }^{81}$, there may be some basis for the oft-repeated claim in many anecdotal reports and in one recent double-blind controlled study ${ }^{92}$ that coloured overlays may be helpful in improving reading performance in children with reading difficulties. For the small, but apparently significant benefits seen for such use coloured overlays or tinted glasses, a neurophysiological model has been proposed that involves the pathways carrying S-cone signals ${ }^{93}$.

The koniocellular regions of the dLGN that carry the S-cone signal also exhibit a slow rhythm that correlates with the brain activity recorded by electroencephalogram ${ }^{94}$. Modifying this rhythm can potentially be used to alter the activity 
of much of the brain itself. If this were true, coming years may reveal the pivotal role played by the koniocellular pathway in a range of brain functions.

\section{Acknowledgements}

We thank Paul R Martin for helpful comments. J.J. and some of our experiments reviewed in this article were supported by project grants 509254 and APP1004102 from the Australian National Health and Medical Research Council. 


\section{References}

1. Wiesel TN, Hubel DH. Spatial and chromatic interactions in the lateral geniculate body of the rhesus monkey. J Neurophysiol 1966; 29: 1115-1156.

2. De Monasterio FM, Gouras P. Functional properties of ganglion cells of the rhesus monkey retina. J Physiol 1975; 251: 167-195.

3. Dreher B, Fukada Y, Rodieck RW. Identification, classification and anatomical segregation of cells with X-like and Y-like properties in the lateral geniculate nucleus of old-world primates. J Physiol 1976; 258: 433-452.

4. Schiller PH, Malpeli JG. Functional specificity of lateral geniculate nucleus laminae of the rhesus monkey. Journal of Neurophysiology 1978; 41: 788-797.

5. Derrington AM, Krauskopf J, Lennie P. Chromatic mechanisms in lateral geniculate nucleus of macaque. J Physiol 1984; 357: 241-265.

6. Roy S, Jayakumar J, Martin PR, Dreher B, Saalmann YB, Hu D, Vidyasagar TR. Segregation of short-wavelength-sensitive (S) cone signals in the macaque dorsal lateral geniculate nucleus. Eur J Neurosci 2009; 30: 1517-1526.

7. Kaplan E, Benardete E. The dynamics of primate retinal ganglion cells. Prog Brain Res 2001; 134: 17-34.

8. Martin PR. Colour through the thalamus. Clin Exp Optom 2004; 87: 249-257.

9. Martin PR, White AJ, Goodchild AK, Wilder HD, Sefton AE. Evidence that blue-on cells are part of the third geniculocortical pathway in primates. Eur J Neurosci 1997; 9: 1536-1541.

10. White AJ, Wilder HD, Goodchild AK, Sefton AJ, Martin PR. Segregation of receptive field properties in the lateral geniculate nucleus of a New-World monkey, the marmoset Callithrix jacchus. J Neurophysiol 1998; 80: 2063-2076. 
11. Metha AB, Lennie P. Transmission of spatial information in S-cone pathways. Vis Neurosci 2001; 18: 961-972.

12. Dacey DM. Morphology of a small-field bistratified ganglion cell type in the macaque and human retina. Vis Neurosci 1993; 10: 1081-1098.

13. Dacey DM, Lee BB. The 'blue-on' opponent pathway in primate retina originates from a distinct bistratified ganglion cell type. Nature 1994; 367: 731735.

14. Dacey DM, Liao HW, Peterson BB, Robinson FR, Smith VC, Pokorny J, Yau KW, Gamlin PD. Melanopsin-expressing ganglion cells in primate retina signal colour and irradiance and project to the LGN. Nature 2005; 433: 749-754.

15. Szmajda BA, Buzas P, Fitzgibbon T, Martin PR. Geniculocortical relay of blueoff signals in the primate visual system. Proc Natl Acad Sci U S A 2006; 103: 19512-19517.

16. White AJ, Solomon SG, Martin PR. Spatial properties of koniocellular cells in the lateral geniculate nucleus of the marmoset Callithrix jacchus. J Physiol 2001; 533: 519-535.

17. Hendry SHC, Yoshioka T. A neurochemically distinct third channel in macaque dorsal lateral geniculate nucleus. Science 1994; 264: 575-577.

18. Hendry SH, Reid RC. The koniocellular pathway in primate vision. Annu Rev Neurosci 2000; 23: 127-153.

19. Tailby C, Solomon SG, Lennie P. Functional asymmetries in visual pathways carrying S-cone signals in macaque. J Neurosci 2008; 28: 4078-4087.

20. Stone J, Dreher B, Leventhal A. Hierarchical and parallel mechanisms in the organization of visual cortex. Brain Res 1979; 180: 345-394. 
21. Cleland BG, Levick WR. Properties of rarely encountered types of ganglion cells in the cat's retina and overall classification. J Physiol 1974; 240: 457-492.

22. Cleland BG, Levick WR, Morstyn R, Wagner HG. Lateral geniculate relay of slowly conducting retinal afferents to cat visual cortex. J Physiol 1976; 255: 299-320.

23. Vidyasagar TR, Kulikowski JJ, Lipnicki DM, Dreher B. Convergence of parvocellular and magnocellular information channels in the primary visual cortex of the macaque. Eur J Neurosci 2002; 16: 945-956.

24. Garey LJ, Dreher B, Robinson SR. The organization of visual thalamus., in Neuroanatomy of Visual Pathways and their Development., B Dreher,SR Robinson, Editors. 1991, Macmillan Press: Houndmills, UK. 176-234.

25. Livingstone M, Hubel D. Segregation of form, color, movement, and depth: anatomy, physiology, and perception. Science 1988; 240: 740-749.

26. Casagrande VA, Kaas JH. The afferent, intrinsic, and efferent connections of primary visual cortex in primates. , in Cerebral Cortex, A Peters,KS Rockland, Editors. 1994, Plenum: New York. 201-259.

27. Creutzfeldt OD, Cortex cerebri. 1993, Goettingen, Germany: Springer-Verlag.

28. Casagrande VA, Yazar F, Jones KD, Ding Y. The morphology of the koniocellular axon pathway in the macaque monkey. Cerebral cortex 2007; 17: $2334-2345$.

29. Mullen KT, Dumoulin SO, McMahon KL, de Zubicaray GI, Hess RF. Selectivity of human retinotopic visual cortex to S-cone-opponent, L/M-coneopponent and achromatic stimulation. Eur J Neurosci 2007; 25: 491-502. 
30. Sumner P, Anderson EJ, Sylvester R, Haynes JD, Rees G. Combined orientation and colour information in human V1 for both L-M and S-cone chromatic axes. NeuroImage 2008; 39: 814-824.

31. Livingstone MS, Hubel DH. Anatomy and physiology of a color system in the primate visual cortex. J Neurosci 1984; 4: 309-356.

32. Yoshioka T, Levitt JB, Lund JS. Independence and merger of thalamocortical channels within macaque monkey primary visual cortex: anatomy of interlaminar projections. Vis Neurosci 1994; 11: 467-489.

33. Callaway EM. Local circuits in primary visual cortex of the macaque monkey. Annu Rev Neurosci 1998; 21: 47-74.

34. Sawatari A, Callaway EM. Convergence of magno- and parvocellular pathways in layer 4B of macaque primary visual cortex. Nature 1996; 380: 442-446.

35. Leventhal AG, Thompson KG, Liu D, Zhou Y, Ault SJ. Concomitant sensitivity to orientation, direction, and color of cells in layers 2,3 , and 4 of monkey striate cortex. J Neurosci 1995; 15: 1808-1818.

36. Ts'o DY, Gilbert CD. The organization of chromatic and spatial interactions in the primate striate cortex. J Neurosci 1988; 8: 1712-1727.

37. Johnson EN, Hawken MJ, Shapley R. The spatial transformation of color in the primary visual cortex of the macaque monkey. Nature Neuroscience 2001; 4: 409-416.

38. Conway BR, Livingstone MS. Spatial and temporal properties of cone signals in alert macaque primary visual cortex. J Neurosci 2006; 26: 10826-10846.

39. Marr D, Vision: A computational investigation into the human representation and processing of visual information1982: MIT Press. 
40. Vidyasagar TR. A neuronal model of attentional spotlight: parietal guiding the temporal. Brain research. Brain research reviews 1999; 30: 66-76.

41. Ungerleider LG, Mishkin M. Two cortical visual systems, in Analysis of Visual Behavior., DJ Ingle, MA Goodale,RJW Mansfield, Editors. 1982, The MIT press: Cambridge. 549-586.

42. Goodale MA, Milner AD. Separate visual pathways for perception and action. Trends Neurosci 1992; 15: 20-25.

43. Roe AW, Chelazzi L, Connor CE, Conway BR, Fujita I, Gallant JL, Lu H, Vanduffel W. Toward a unified theory of visual area v4. Neuron 2012; 74: 1229.

44. Maunsell JH, Nealey TA, DePriest DD. Magnocellular and parvocellular contributions to responses in the middle temporal visual area (MT) of the macaque monkey. J Neurosci 1990; 10: 3323-3334.

45. Wandell BA, Poirson AB, Newsome WT, Baseler HA, Boynton GM, Huk A, Gandhi S, Sharpe LT. Color signals in human motion-selective cortex. Neuron 1999; 24: 901-909.

46. Morand S, Thut G, de Peralta RG, Clarke S, Khateb A, Landis T, Michel CM. Electrophysiological evidence for fast visual processing through the human koniocellular pathway when stimuli move. Cerebral cortex 2000; 10: 817-825.

47. Gegenfurtner KR, Kiper DC, Beusmans JM, Carandini M, Zaidi Q, Movshon JA. Chromatic properties of neurons in macaque MT. Vis Neurosci 1994; 11: $455-466$.

48. Seidemann E, Poirson AB, Wandell BA, Newsome WT. Color signals in area MT of the macaque monkey. Neuron 1999; 24: 911-917. 
49. Barberini CL, Cohen MR, Wandell BA, Newsome WT. Cone signal interactions in direction-selective neurons in the middle temporal visual area (MT). J Vision 2005; 5: 603-621.

50. Riecansky I, Thiele A, Distler C, Hoffmann KP. Chromatic sensitivity of neurones in area MT of the anaesthetised macaque monkey compared to human motion perception. Exp Brain Res 2005; 167: 504-525.

51. Jayakumar J, Roy S, Dreher B, Vidyasagar TR. S-cone signals to area MT in the macaque: Some bypass area V1 and others do not. in Society for neuroscience annual meeting. 2009. Chicago.

52. Nassi JJ, Lyon DC, Callaway EM. The parvocellular LGN provides a robust disynaptic input to the visual motion area MT. Neuron 2006; 50: 319-327.

53. Dhar P, Mehra RD, Sidhartan V, Sharma K. Parvalbumin and calbindin D-28K immunoreactive neurons in area MT of rhesus monkey. Exp Brain Res 2001; 137: 141-149.

54. Sincich LC, Park KF, Wohlgemuth MJ, Horton JC. Bypassing V1: a direct geniculate input to area MT. Nature Neuroscience 2004; 7: 1123-1128.

55. Rodman HR, Gross CG, Albright TD. Afferent basis of visual response properties in area MT of the macaque. I. Effects of striate cortex removal. J Neurosci 1989; 9: 2033-2050.

56. Girard P, Salin PA, Bullier J. Response selectivity of neurons in area MT of the macaque monkey during reversible inactivation of area V1. J Neurophysiol 1992; 67: 1437-1446.

57. Rodman HR, Gross CG, Albright TD. Afferent basis of visual response properties in area MT of the macaque. II. Effects of superior colliculus removal. J Neurosci 1990; 10: 1154-1164. 
58. Marrocco RT, Li RH. Monkey superior colliculus: properties of single cells and their afferent inputs. J Neurophysiol 1977; 40: 844-860.

59. Schiller PH, Malpeli JG. Properties and tectal projections of monkey retinal ganglion cells. J Neurophysiol 1977; 40: 428-445.

60. Martin PR, Tailby C, Solomon SG, Cheong SK, Pietersen ANJ. Contribution of short wavelength sensitive (S or "Blue") cones to visual responses in superior colliculus, Proceedings of the Australian Neuroscience Society. 2012.. p. 139.

61. Schmid MC, Mrowka SW, Turchi J, Saunders RC, Wilke M, Peters AJ, Ye FQ, Leopold DA. Blindsight depends on the lateral geniculate nucleus. Nature 2010; 466: $373-377$.

62. Mizuno N, Itoh K, Uchida K, Uemura-Sumi M, Matsushima R. A retinopulvinar projection in the macaque monkey as visualized by the use of anterograde transport of horseradish peroxidase. Neurosci Lett 1982; 30: 199203.

63. Itaya SK, Van Hoesen GW. Retinal projections to the inferior and medial pulvinar nuclei in the Old-World monkey. Brain Res 1983; 269: 223-230.

64. Nakagawa S, Tanaka S. Retinal projections to the pulvinar nucleus of the macaque monkey: a re-investigation using autoradiography. Exp Brain Res 1984; 57: 151-157.

65. Cowey A, Stoerig P, Bannister M. Retinal ganglion cells labelled from the pulvinar nucleus in macaque monkeys. Neuroscience 1994; 61: 691-705.

66. O'Brien BJ, Abel PL, Olavarria JF. The retinal input to calbindin-D28k-defined subdivisions in macaque inferior pulvinar. Neurosci Lett 2001; 312: 145-148. 
67. Warner CE, Goldshmit Y, Bourne JA. Retinal afferents synapse with relay cells targeting the middle temporal area in the pulvinar and lateral geniculate nuclei. Front Neuroanat 2010; 4: 8 .

68. Sincich LC, Horton JC. Input to V2 thin stripes arises from V1 cytochrome oxidase patches. J Neurosci 2005; 25: 10087-10093.

69. Sincich LC, Horton JC. Pale cytochrome oxidase stripes in V2 receive the richest projection from macaque striate cortex. J Comp Neurol 2002; 447: 1833.

70. Weiskrantz L, Warrington EK, Sanders MD, Marshall J. Visual capacity in the hemianopic field following a restricted occipital ablation. Brain 1974; 97: 709728.

71. Cowey A. The 30th Sir Frederick Bartlett lecture. Fact, artefact, and myth about blindsight. The Quarterly journal of experimental psychology. A, Human experimental psychology 2004; 57: 577-609.

72. Vakalopoulus C. A theory of blindsight-the anatomy of the unconscious: a proposal for the koniocellular projections and intralaminar thalamus. Med Hypotheses 2005; 65: 1183-1190.

73. Weiskrantz L. Sources of blindsight. Science 1993; 261: 494.

74. Rosa MG, Tweedale R, Elston GN. Visual responses of neurons in the middle temporal area of new world monkeys after lesions of striate cortex. J Neurosci 2000; 20: 5552-5563.

75. Alexander I, Cowey A. The cortical basis of global motion detection in blindsight. Exp Brain Res 2009; 192: 407-11.

76. Alexander I, Cowey A. Edges, colour and awareness in blindsight. Consciousness and cognition 2010; 19: 520-533. 
77. Casagrande VA, Khaytin I, Boyd J. The evolution of parallel pathways in the brains of primates. In Evolutionary Neuroscience. Kaas JH Editor. 2009: Academic press. 871-892.

78. Nathans J. The evolution and physiology of human color vision: insights from molecular genetic studies of visual pigments. Neuron 1999; 24:299-312.

79. Payne BR. Evidence for visual cortical area homologs in cat and monkey. Cereb Cortex 1993; 3: 1-25.

80. Dreher B, Wang C, Turlejski KJ, Djavadian RL, Burke W. Area PMLS and 21a of cat visual cortex: Two functionally distinct areas. Cereb Cortex 1996; 6:585599.

81. Li JC, Sampson GP, Vidyasagar TR. Interactions between luminance and colour channels in visual search and their relationship to parallel neural channels in vision. Exp Brain Res 2007; 176: 510-518.

82. Cheng A, Eysel UT, Vidyasagar TR. The role of the magnocellular pathway in serial deployment of visual attention. Eur J Neurosci 2004; 20: 2188-2192.

83. Saalmann YB, Pigarev IN, Vidyasagar TR. Neural mechanisms of visual attention: how top-down feedback highlights relevant locations. Science 2007; 316: 1612-1615.

84. Bisley JW. The neural basis of visual attention. J Physiol 2011; 589: 49-57.

85. Facoetti A, Paganoni P, Turatto M, Marzola V, Mascetti GG. Visual-spatial attention in developmental dyslexia. Cortex 2000; 36: 109-123.

86. Vidyasagar TR. Neural underpinnings of dyslexia as a disorder of visuo-spatial attention. Clin Exp Optom 2004; 87: 4-10.

87. Bosse ML, Tainturier MJ, Valdois S. Developmental dyslexia: the visual attention span deficit hypothesis. Cognition 2007; 104: 198-230. 
88. Laycock R, Crewther SG, Crewther DP. A role for the 'magnocellular advantage' in visual impairments in neurodevelopmental and psychiatric disorders. Neuroscience and biobehavioral reviews 2007; 31: 363-376.

89. Facoetti A, Trussardi AN, Ruffino M, Lorusso ML, Cattaneo C, Galli R, Molteni M, Zorzi M. Multisensory spatial attention deficits are predictive of phonological decoding skills in developmental dyslexia. J Cogn Neurosci 2010; 22: $1011-25$.

90. Vidyasagar TR, Pammer K. Dyslexia: a deficit in visuo-spatial attention, not in phonological processing. Trends Cog Sci 2010; 14: 57-63.

91. Stein J, Walsh V. To see but not to read; the magnocellular theory of dyslexia. Trends Neurosci 1997; 20: 147-152.

92. Ray NJ, Fowler S, Stein JF. Yellow filters can improve magnocellular function: motion sensitivity, convergence, accommodation, and reading. Ann N Y Acad Sci 2005; 1039: 283-293.

93. Vidyasagar TR. Attentional gating in primary visual cortex: a physiological basis for dyslexia. Perception 2005; 34: 903-911.

94. Cheong SK, Tailby C, Martin PR, Levitt JB, Solomon SG. Slow intrinsic rhythm in the koniocellular visual pathway. Proc Natl Acad Sci U S A 2011; 108: 14659-14663. 


\section{Figure Legends}

Figure 1 demonstrates a technique of easy visualisation of the koniocellular strands in the parvocellular layers of macaque's dorsal lateral geniculate nucleus (dLGN). Figure 1 A shows a coronal section through dLGN of macaque stained for Nissl substance. Note a reconstructed electrode track indicating the position within the dLGN where different types of cells were encountered. The koniocellular layers (K1K6) are the relatively pale areas compared to the magnocellular or the parvocellular layers. Figure 1B shows the photograph of the same coronal section through the dLGN but this time defocussed using a Gaussian blur filter. The two arrows mark the recording positions of two Blue-ON units (open blue circles). Cell 1 was located in the intercalated layer, K5. Cell 2 appears to lie within the koniocellular strand that straddles between $\mathrm{K} 4$ and $\mathrm{K} 5$, which becomes evident with the simple blurring technique.

Figure 2 illustrates the different pathways taken by the S-cone signals to reach the extrastriate cortical areas cortex. Retinal ganglion cells (RGCs) which receive S-cone signals project to the koniocellular regions of the dorsal lateral geniculate nucleus (dLGN). From the dLGN, these signals are sent to the extrastriate middle temporal area (area MT) either directly or relayed through the primary visual cortex (V1). The koniocellular inputs to V1 terminate in layer 1 and the cytochrome oxidase rich blobs in layers $2 / 3$ with some 'spill-over' into the cytochrome oxidase poor interblob regions in layers $2 / 3$. These well-known projections of S-cone signals are marked with blue arrows. From the blob and interblob regions in V1, these signals are sent via 
the thin and the pale cytochrome oxidase stripes (marked with black arrows) to the extrastriate visual area V4. The likely pathway that these signals reach area MT is unclear and can be either through the layer 4B neurones that project directly to area MT or via the thick and/or pale cytochrome oxidase stripes of area V2. The S-cone signals that reach layer 1 of V1 may contact the apical dendrites of pyramidal cells of layer 3 and layer 4B. These putative pathways are coloured in purple. 
A

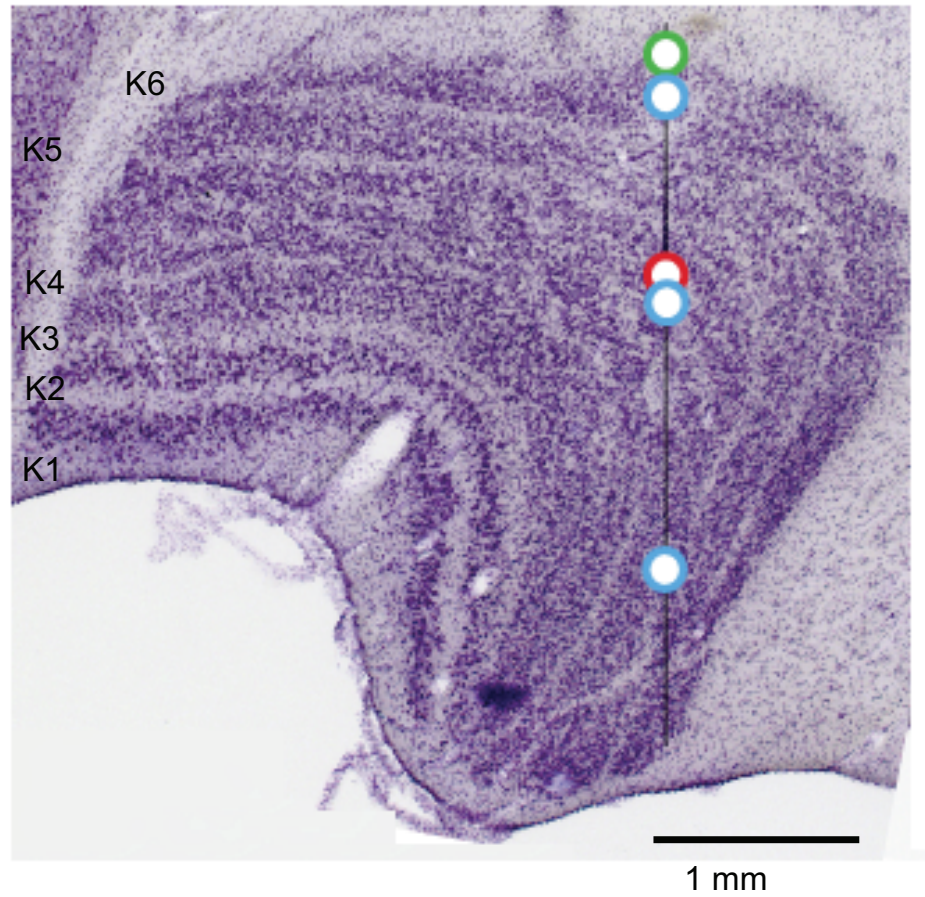

Figure 1 Jayakumar et al
B

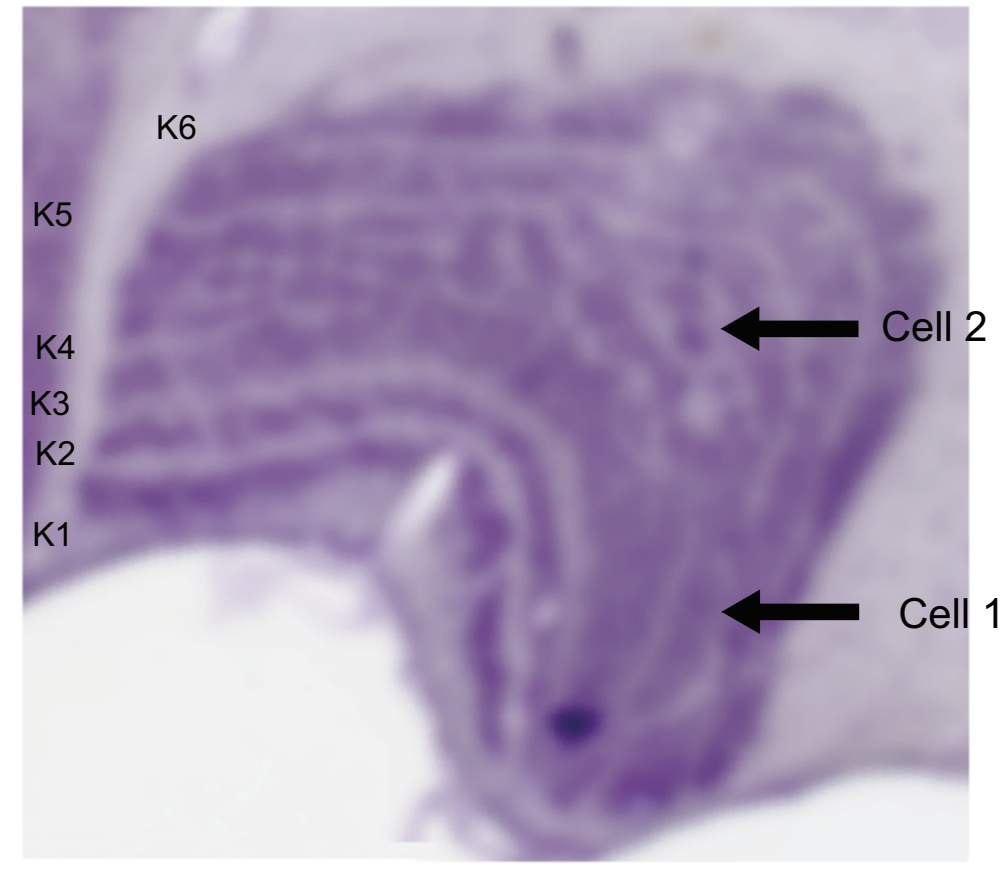




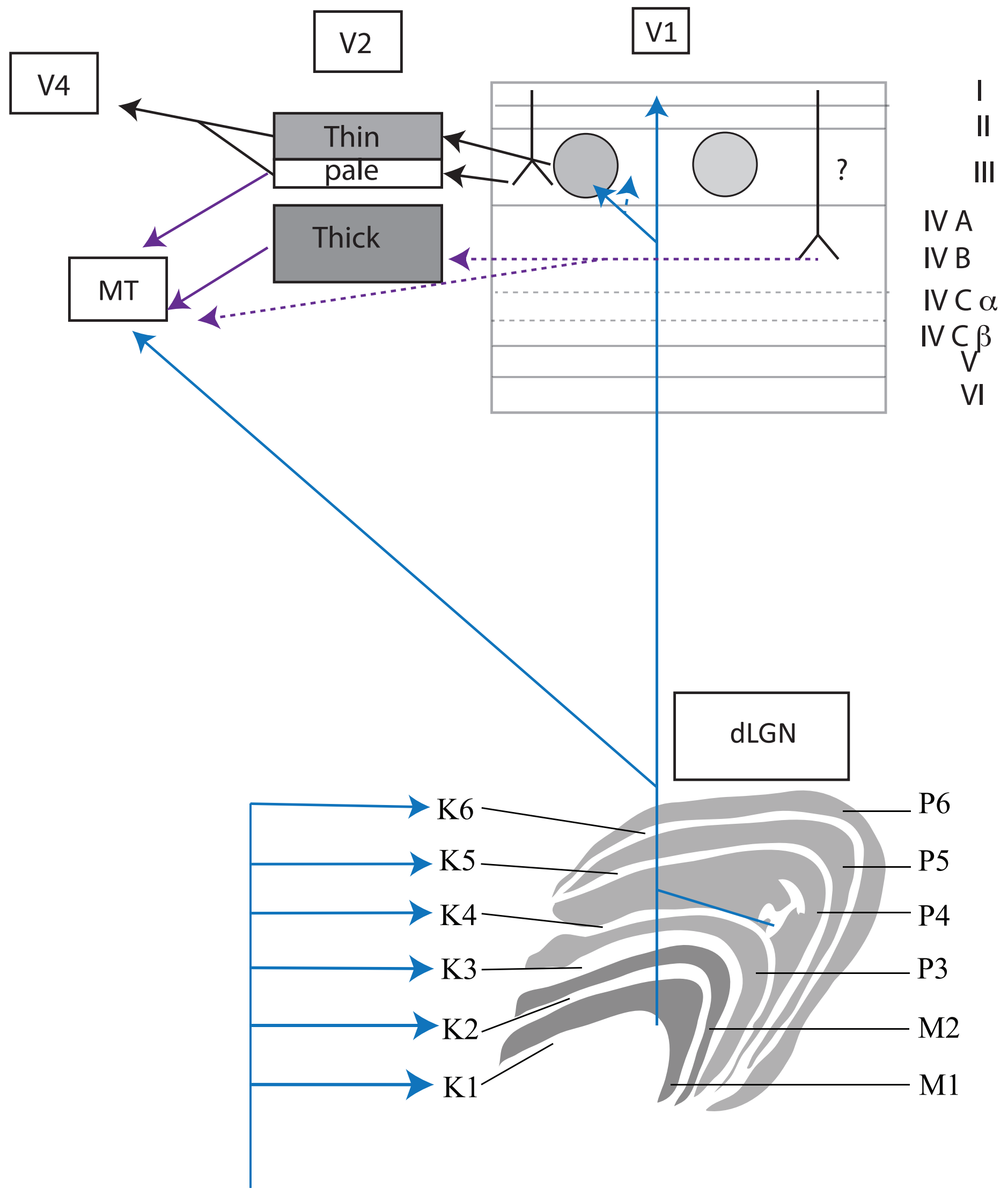

Retina

Figure 2 Jayakumar et al 


\section{University Library}

\section{- M M I N E R VA A gateway to Melbourne's research publications}

Minerva Access is the Institutional Repository of The University of Melbourne

Author/s:

Jayakumar, J;Dreher, B;Vidyasagar, TR

Title:

Tracking blue cone signals in the primate brain

Date:

2013-05-01

Citation:

Jayakumar, J., Dreher, B. \& Vidyasagar, T. R. (2013). Tracking blue cone signals in the primate brain. CLINICAL AND EXPERIMENTAL OPTOMETRY, 96 (3), pp.259-266. https:// doi.org/10.1111/j.1444-0938.2012.00819.x.

Persistent Link:

http://hdl.handle.net/11343/39658 